\title{
A hermenêutica e a origem dos faxinais
}

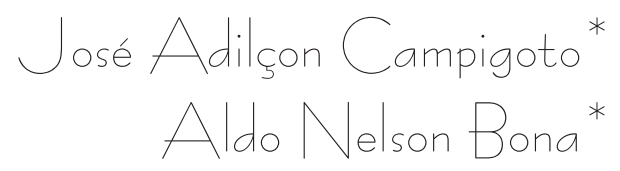

Neste texto, pretende-se discutir as relações entre a produção do conhecimento histórico e a arte da interpretação, a partir das ponderações feitas por Hans-Georg Gadamer, em Verdade e método. O ponto de vista implica, sumariamente, abraçar a hermenêutica como atitude investigativa e propor-se à superação de alguns artificios metodológicos de interpretação, tais como a filologia ${ }^{1}$, o psicologismo ${ }^{2}$ e o contextualismo ${ }^{3}$. Trata-se, pois, de um estilo em que as interrogações sobre os procedimentos interpretativos são postas em primeiro plano e que se quer estender ao campo da história cultural.

A bem da compreensão, partiremos de um objeto palpável, visando prevenir o figurativismo, uma vez que muitas tentativas de conceituação da história cultural, assim como as discussões sobre as dinâmicas da compreensão, por si mesmas, instigam à abstração. O objeto escolhido para tal ancoragem, então, é o sistema de faxinal, que consiste em certo modo de utilização comum das terras para a criação de animais, existente na região sul do Brasil e que se tem classificado como manifestação cultural pertencente à categoria dos povos tradicionais.

\footnotetext{
* Professor do Departamento de História da Universidade Estadual do Centro Oeste do Paraná. Membro do Grupo de Estudos em História Cultural.

${ }^{1}$ Arte de investigar a origem das palavras e método que objetiva compreender o fragmento a partir da totalidade textual.

${ }^{2}$ Modo de interpretação que objetiva atingir o que se passava na mente do autor no momento da escrita.

${ }^{3}$ Modo de interpretação que busca reconstruir o sentido a partir do contexto da escrita.
} 
A escolha deste fenômeno vincula-se ao empenho de cientistas pertencentes a várias áreas do conhecimento na investigação e no reconhecimento legal destes chamados grupos marginais. Diligência que, de certo modo, apresenta-se como desafio aos historiadores da cultura, porque nos parece que em nenhuma outra época se discorreu tão intensamente sobre o tema e se examinou tão interdisciplinarmente estes grupos, classificados, também, como excluídos da história.

A categoria é razoavelmente ampla. Abriga a diversidade de grupos e tipos de povoamento existentes em determinado território ou país, marginalizados socialmente e, digase, ao mesmo tempo, ainda precariamente considerados no âmbito das políticas de escrita. Tratamento tangencial que pode dever-se à utilização de esquemas teóricos gerais e globalizantes, implicando a negligência e, por certo, o menosprezo em relação às peculiaridades, às características e às singularidades que nos permitem identificá-los como objetos ou sujeitos de estudo, isto é, fenômenos isoláveis. No caso do Brasil, tal noção abrange, por exemplo, os indígenas, os quilombolas, os caiçaras, os açorianos, os babaçueiros, os caboclos, os caipiras, os sertanejos, as quebradeiras de coco, os pantaneiros, os jangadeiros, os pescadores artesanais, os seringueiros, os vargeiros, os faxinalenses e muitos outros. A demanda consiste em que estes grupos, agora, são postos em relevo exatamente por conta de suas especificidades, tais como: a forma de uso e posse da terra, o aproveitamento ecológico dos recursos naturais, o cultivo da vida comunitária e a preservação de memória comum. Por conta dessa tendência, aponta-se o sistema faxinal como acontecimento singular, distinto pela utilização coletiva da terra para a criação de animais. O caráter grupal se expressa na forma de criadouro comum. ${ }^{4}$

De fato, podemos dizer que o estabelecimento de acordos para a destinação e a manutenção de certo território em função da criação de animais pertencentes a pessoas que não

\footnotetext{
${ }^{4}$ Ver CHANG, M.Y. Sistema Faxinal - uma forma de organização camponesa em desagregação no Centro Sul do Paraná. Dissertação de mestrado, UFRJ, Rio de Janeiro, 1985. 
são as proprietárias legais da terra é uma das características básicas do que se costuma chamar de faxinal, na região sul do Brasil. Estes espaços têm atraído a atenção, por exemplo, de engenheiros florestais e ambientalistas que investigam, principalmente, os seus aspectos ecológicos. Cientistas sociais e sócio-ambientalistas insistem na singularidade cultural e histórica do sistema e, neste ponto, iniciam-se os desafios para a escrita da história destes povos, na perspectiva cultural. Afirma-se, por exemplo, tratar-se de agrupamentos humanos instituidores de territórios sociais ou que podem ser classificados como povos tradicionais, ou ainda, que devem ser considerados sob a categoria de comunidades performáticas e assim por diante.

No âmbito da política institucional, e por meio do decreto estadual $n^{\circ} 3.446 / 97$, do governo do Paraná, declarouse os faxinais como áreas especiais de uso regulamentado (ARESUR), seguindo as mesmas diretrizes de utilização das áreas de proteção ambiental (APAS). Era o ano de 1997. O decreto prevê mecanismos de repasse de ICMs ecológico às populações residentes nestas áreas. ${ }^{5}$ Passaram-se oito anos e os representantes destes grupos foram incluídos na Comissão Nacional de Povos e Populações Tradicionais do Ministério do Meio Ambiente. Bom avanço... Mas precisamos considerar que, conforme relatório técnico do instituto ambiental do Paraná (IAPAR), apenas quarenta e quatro das áreas mapeadas foram consideradas como remanescentes de faxinais, ou seja, espaços mantenedores da organização social típica do sistema e da paisagem silvestre de araucária. Conforme o relatório, cinquenta e seis deles preservam apenas a paisagem de florestas nativas e em cinquenta e duas destas áreas o sistema foi extinto, uma vez que perderam totalmente suas características originais. ${ }^{6}$ Estima-se que há dez anos exis-

\footnotetext{
${ }^{5}$ Esse repasse é feito às prefeituras municipais onde os faxinais estão localizados, sendo a aplicação dos recursos variável de município para município, chegando a ser polêmica e bastante questionável em alguns deles.

${ }^{6}$ MARQUES, C. L. G. Levantamento preliminar sobre o sistema faxinal no estado do Paraná. Guarapuava, 2004. (Relatório Técnico) Instituto Ambiental do Paraná.
} 
tiam cerca de cento e cinquenta desses sistemas em funcionamento, significando que, na década passada, arruinou-se uma dezena destes grupos, a cada ano.

Os números apresentados sugerem a sinistra história recente dos faxinais. Os cientistas sociais, de modo geral, evocam a trama na qual a modernização da agricultura e o desenvolvimento do capitalismo no campo representam os vilões. Na mesma urdidura, porém, indica-se o movimento contrário, isto é, a organização destes povos em função do reconhecimento jurídico e da re-significação política. Destaca-se, por exemplo, a Articulação Puxirão, criada em 2005, como resultado do I Encontro dos Faxinais do Paraná. O movimento que agiliza as reivindicações dos faxinalenses, sendo formado por membros das Associação de Moradores dos faxinais. Portanto, fala-se de desagregação e de organização.

Neste cenário de declínio e organização, emerge o discurso da identidade faxinalense. Delineiam-se definições, ensaiam-se classificações e projetam-se conceitos. Investigase o estado atual, buscam-se as origens e descrevem-se os percursos históricos. Vemos, assim, o desenrolar da construção do sentido, mas há, neste processo de constituição, evidente paradoxo: o dito aceleramento da derrocada dos faxinais significa a sua manifestação, ou seja, a sua exibição como objeto histórico.

Como historiadores interessados na cultura popular e que não querem deixar-se levar pelas armadilhas da linguagem, devemos considerar-nos parte deste movimento, ainda mais por ser a chamada história cultural campo bastante amplo e parcialmente definido. Como intérpretes, somos parte dessa coisa que se mostra no desaparecimento anunciado.

Pode ser mesmo um sentimento de contra-senso experimentado por quem se aproxima de semelhantes objetos. Contradição às vezes justificada por razões estéticas tal como: os historiadores têm certa "queda" pelos oprimidos. Outras vezes, apresentam-se razões políticas, mesmo diante da certeza de que nestes casos urgentes, sentar e escrever não são a melhor forma de militância. Por fim, indicam-se

130 Revista de História Regional 14(2): 127-153, Inverno, 2009 
razões éticas, menos convincentes ainda, porque, os valores éticos não se constroem na hora crítica da urgência. Pode ser uma mescla de tudo isso, mas tal discussão nos conduziria, talvez, a algum campo demasiadamente abstrato.

Nossa questão aqui se restringe a determinado aspecto menos generalizante, pois se trata de compreender a construção do sentido histórico, isto é, consiste em investigar como se conta a história dos faxinais (e por extensão, dos povos excluídos) num momento que representa, pelo menos para alguns, a aceleração do desaparecimento do sistema. O exercício hermenêutico de compreensão dos fenômenos também nos leva a considerar que acontecimentos do tipo criação de animais em comum podem ser interpretados coerentemente como obras do acaso ou resultados de ações mágicas. Mas a perspectiva histórica indica a convicção de que tais fenômenos desenvolveram-se ao longo do tempo, ponto sobre o qual concordam os pesquisadores em geral, e não somente historiadores.

Então, o sistema de faxinal é relacionado, por exemplo, às terras comunais ${ }^{7}$, áreas de uso coletivo que, se diz, foi prática corriqueira na Ilha de Santa Catarina, desde a chegada dos imigrantes açorianos, até há pouco tempo. A conclusão pode ser automática: as terras comunais fazem parte da tradição açoriana e o uso popular da terra descende do arquipélago dos Açores e de Portugal. ${ }^{8}$ Afirma-se, também, que o ager publicus, ou a atitude de usar pastagens em comum, existia entre os romanos e os povos nórdicos. O caso mais conhecido, talvez, diga respeito aos ingleses e foi celebrizado pelo estudo de Karl Marx sobre a transformação das terras de uso comum em propriedades privadas, processo que se estendeu entre os séculos XVI e XVIII. Na emergência do discurso da identidade faxinalense é prosaico, mas não descartável, o vínculo com a Europa.

${ }^{7}$ Ver DE CAMPOS, Nazareno José. Terras Comunais na Ilha de Santa Catarina. Florianópolis: Ed. da UFSC, 1991.

${ }^{8}$ Ver FIGUEIREDO, Aline. Terras comunais urbanismo. Disponivel em: http:// www.arq.ufsc.br/urbanismo1/2005-1/final/final_af.pdf. 
Há, no entanto, pesquisadores que argumentam que o "berço dos faxinais" está nas culturas indígenas do Sul do Brasil. De fato, o sentido dessa tese é igualmente lógico e completo uma vez que os ameríndios usavam as terras coletivamente, mas, então, algumas questões nada desprezíveis tornam-se inevitáveis: porque estabelecer relações entre os faxinais e a origem européia? Não estaria funcionando, aí, certo mecanismo de menosprezo aos povos nativos? Não seria este caso típico de um maquinismo cultural colonialista, incorporado e reproduzido, até o presente, pelo historiador colonizado?

Nesta linha interpretativa, os faxinais são apontados por Maria Magdalena Nerone como herança cultural da ocupação territorial implantada pelos jesuítas espanhóis na parte ocidental do Paraná: o sistema utilizado nas reduções jesuíticas. Segundo esta hipótese, após a destruição das reduções, os indígenas reproduziram o sistema e, no contato com a cultura não indígena, transmitiam a sua experiência de vida comunitária. Deste modo, os faxinais já existiam desde aquele tempo, no Brasil Sul. ${ }^{9}$ Mas existem divergências. Man Yu Chang, ${ }^{10}$ por exemplo, afirma que os traços básicos da cultura faxinalense estavam presentes na região da mata com araucária antes da política de incentivo à imigração européia "implementada" nos séculos XIX e XX. Conforme esta versão, o sistema faxinal, com as suas características próprias, entretanto, só começa a ser verdadeiramente formado a partir do momento em que se estabeleceu o contato entre a população que ali vivia e o imigrante europeu, nos finais do século XIX. Por consequência, os sujeitos responsáveis pela hibridação cultural resultante são, principalmente, os imigrantes de origem eslava. Ainda assim, a controvérsia continua.

\footnotetext{
${ }_{9}$ Ver NERONE, Maria M. Terras de plantar, terras de criar - Sistema Faxinal: Rebouças - 1950-1997. Assis, 2000. 286 f. Tese (Doutorado em História) - Universidade Estadual Paulista.

${ }^{10}$ Atualmente é Coordenadora de Mudanças Climáticas na Secretaria de Estado do Meio Ambiente e Recursos Hídricos do Paraná. 
Segundo Löwen Sahr e Iegelski, ${ }^{11}$ a origem dos faxinais vincula-se à população existente na região no século XVIII, ou seja, aos caboclos. Aqui, os imigrantes dos séculos XIX e XX teriam se apropriado da cultura cabocla e, desse contato, originaram-se os faxinais ucranianos e poloneses. ${ }^{12}$

Poderíamos, então, abordar o faxinal como fenômeno de fronteira cultural, mas as culturas indígenas permaneceriam excluídas nesta tentativa de definição das origens. Ora, sabemos da inexistência de culturas puras. Acontece que o conceito de hibridismo cultural agravaria o problema, uma vez que híbrido é a planta ou animal estéril que não pode procriar. Precisariamos, então, imaginar ou definir quais são as culturas férteis. Além disso, a investigação da origem tem conduzido os pesquisadores que vinculam os faxinais à origem indigena a recorrerem à intervenção dos jesuítas, ou seja, a estabelecerem o vínculo com o velho continente por meio da ação missionária dos 'discipulos de Loyola'. Percebemos, agora, a pesquisa da origem dos faxinais como esforço de constituição do sentido. ${ }^{13}$ Podemos supor que a investigação da origem esteja vinculada à tradição jurídica expressa

\footnotetext{
${ }^{11}$ LÖWEN SAHR, C.; IEGELSKI, F. O Sistema Faxinal no Municipio de Ponta Grossa: diretrizes para a preservação do ecossistema, do modo de vida, da cultura e das identidades das comunidades e dos espaços faxinalenses. Ponta Grossa: Prefeitura Municipal de Ponta Grossa, 2003, 108 p. (Relatório Técnico).

${ }^{12}$ Estima-se que a Grande Imigração, do final do século XIX e início do XX, representou a introdução de cerca de 57 milhões de eslavos nas Américas, na Austrália e na Nova Zelândia. A maioria desses sujeitos era composta de habitantes de algumas áreas rurais, localizadas na região da Europa Centro-Oriental e Mediterrânea. O Brasil era um dos países alvos desses cursos imigratórios. Estima-se que, entre os anos de 1889 e 1910, vieram para o Paraná cerca de 40.000 poloneses e 20.000 ucranianos, sendo que 35.000 desses eslavos estabeleceram-se na região dos pinhais adotando, inclusive, o sistema de faxinal. Atualmente, no Brasil, há mais de 300.000 descendentes de ucranianos, dos quais $90 \%$ estão no Paraná, destacando o Município de Prudentópolis, no qual a grande maioria dos imigrantes se estabeleceu.

${ }^{13}$ A opção pela terminologia "constituição de sentido" evidencia o horizonte de compreensão segundo o qual o sentido não é algo pertencente à coisa ou fenômeno estudado e que poderia ser "descoberto" num processo de investigação. Pelo contrário, as coisas não têm o sentido em si mesmas; o sentido é algo atribuído à coisa ou fenômeno pelo sujeito (ou pelos sujeitos) que o considera. Assim, o debate em torno do fenômeno dos faxinais é um esforço de constituição de sentido.
} 
no enunciado de que origo rei inspici debet ${ }^{14}$ e pensar, também, que o cuidado da gênese consiste numa das formas de constituição dos sentidos. ${ }^{15}$ Foucault se indaga sobre a rejeição de Nietzsche à pesquisa da origem, indicando que:

... a pesquisa, nesse sentido, se esforça para recolher nela a essência exata da coisa, sua mais pura possibilidade, sua identidade cuidadosamente recolhida em si mesma, sua forma imóvel e anterior a tudo o que é externo, acidental, sucessivo. Procurar uma tal origem e tentar reencontrar 'o que era imediatamente', 'o aquilo mesmo' de uma imagem exatamente adequada a si. É tomar por acidental todas as peripécias que puderam ter acontecido, todas as astúcias, todos os disfarces; é querer tirar as máscaras para desvelar, enfim, uma identidade primeira. Ora, se o genealogista tem o cuidado de escutar a história em vez de acreditar na metafísica, o que é que aprende? Que atrás das coisas há 'algo inteiramente diferente': não seu segredo essencial, mas o segredo de que elas são sem essência, ou que sua essência foi construída peça por peça a partir de figuras que lhe eram estranhas. ${ }^{16}$

Sigamos, imediatamente, Foucault. Escutemos a história, considerando que gênese e genealogia representam procedimentos de constituição do sentido das coisas. Do ponto de vista geral da hermenêutica, o sentido se completa sempre que a compreensão se efetua, ou seja, o ato de compreender segue uma dinâmica estável: o movimento que vai da parte ao todo e do todo à parte. Assim, sempre que os investigadores - intérpretes dos faxinais - vinculam a cultura faxinalense às raízes europeias adotam o velho continente como a totalidade histórica. A afirmação deste conjunto assim como a confirmação desta procedência pode ser examinada como fenômeno da escrita eurocêntrica da história. Aplica-se o mesmo princípio para as teses das origens ameríndias do faxinal. A perspectiva genealógica nos auxilia a evitar tais

\footnotetext{
${ }^{14}$ A origem da coisa deve ser examinada.

${ }^{15}$ Ver FOUCAULT, Michel. Microfisica do poder. Rio de Janeiro: Edições Graal, 1992. p 17.

${ }^{16}$ Idem, ibidem.
} 
armadilhas da linguagem, contornáveis igualmente pela utilização da atitude filosófica hermenêutica.

O estilo hermeneuta evidencia os procedimentos relacionados à compreensão por meio da apreciação de alguns termos implicados na abordagem genética dos faxinais, tais como: cultura, história, origem, sujeito e sociedade. Uma boa entrada para a discussão do problema talvez seja o século XIX, mas não a ocasião e nem o contexto do surgimento da história ciência. Mais esclarecedor e menos genético será averiguar os questionamentos enfrentados pelos defensores e praticantes do conhecimento histórico naquele período: a polêmica do método. Trata-se de acontecimento decisivo por que, então, se apresentava outra forma de trabalho, pode-se dizer frontalmente contrário à investigação das origens e à função desempenhada pelo sujeito histórico na construção deste saber. A Europa foi o cenário.

Ponderemos, inicialmente, que a palavra história significava algo aquém do tempo vivido e da disciplina ou área do conhecimento que se propõe investigar o passado, ou o presente. Tratava-se, fundamentalmente, de um procedimento investigativo, ou seja, de uma fórmula aplicada para compreender e conferir sentido aos fenômenos investigados. Esta arte, aplicada ainda atualmente, consiste em refazer as distintas etapas dos fenômenos de conhecimento para descobrir sua evolução e desenvolvimento. Seus usuários e defensores partem do pressuposto de que todo fato tem a causa que lhe é anterior e que, para conhecer algo, em essência, se faz necessário revelar sua história, ou seja, percorrer as etapas principais de seu desenvolvimento, restabelecendo as conexões históricas fundamentais de cada estágio. A aplicação de tal procedimento permitiria a visão da trajetória temporal do objeto e seus condicionamentos aos diferentes períodos do tempo. A fórmula histórica é usada como base dos métodos lógicos, em geral. ${ }^{17}$

${ }_{17}$ OCHOA G., Ana Beatriz. Métodos. Disponivel em: http://www.monografias. com/trabajos $11 /$ metods/metods.shtml\#HISTO. 
A investigação hermenêutica sobre a compreensão histórica causa a impressão de que a questão do método histórico tem recebido tratamento superficial nos textos que se referem, por exemplo, às escolas históricas. Geralmente, afirma-se que a escola metódica perdeu terreno para outras formas de escrita da história devido às críticas ao seu caráter positivista, ao seu enfoque restrito aos acontecimentos políticos e à sua intransigência na forma de conceber a documentação.

Então, recorre-se ao texto de François Simiand, Méthode Histórique et Sciences Sociales, publicado em 1903, frequentemente tomado como exemplo das criticas que os sociólogos fizeram contra os historiadores do início do século XX. Aponta-se que:

Simiand combatia a história que ele denominava de historicizante: método científico como meio e fim, cuja tarefa era estabelecer os fatos de acordo com as regras do método erudito de crítica e classificação das fontes. Ele combatia os ídolos da tribo dos historiadores: ídolo politico (historia eminentemente política), ídolo individual (os feitos dos grandes homens) e ídolo cronológico (mito das origens). ${ }^{18}$

Mas Simiand era seguidor de Émile Durkheim. Podemos dizer que os debates entre os durkheimnianos e os defensores da escola metódica constituem acontecimento mais amplo do que o desenrolar de disputas politicas e institucionais no âmbito acadêmico. É o que se pode deduzir examinando duas obras de referência sobre o tema e apresentadas ao público naquele período. A primeira delas é Methode Historique Appliquée aux Sciences Sociales, publicada em 1901, por Charles Seignobos. A outra, de autoria de Simiand, citada anteriormente, substituiu o termo "aplicado às" pelo conectivo " $e$ ". Trata-se, portanto, daquela situação em que se defrontaram os historiadores com outra proposta de com-

${ }^{18}$ SILVA, Fernando Teixeira da. História e ciências sociais: zonas de fronteira. In, Revista História. V. 24 nº. 1, São Paulo: Unesp, 2005. p 1. 
preensão da história, outra totalidade compreensiva, isto é, o reino do social, como o chamou Durkheim. A proposta emergia e consolidava-se por meio de procedimento metodológico diferente daquele até então seguido pelos investigadores da história.

Durkheim dedicou-se à defesa da aplicação do método analítico ao campo das ciências humanas. A principal tese de sua teoria sociológica, o princípio da "determinância" social, derivou do emprego de seu método preferido aos fenômenos humanos. Consistia na identificação de um todo, que deveria ser dividido em partes para estudá-las e examiná-las, separadamente, com o fim de estabelecer conexões entre elas. A análise - nome do método - efetuava-se a partir das vinculações estabelecidas entre a totalidade pré-determinada e os elementos que a conformam.

Pode-se dizer que Durkheim concebeu o fenômeno humano como conjunto composto por elementos biológicos, psíquicos e sociais. Então, por meio de algumas metáforas como a do bronze, ${ }^{19}$ ilustrou o que seria a decomposição analítica do fenômeno humano. Escreveu que a dureza do bronze: “... não reside no cobre, no estanho ou no chumbo que serviram para o formar e que são corpos moles e dúcteis, mas sim na sua mistura...". ${ }^{20}$ Isto significava dizer que o fenômeno social deveria ser estudado como elemento em separado, ou seja, como a própria totalidade. A proposta prescindia, ou tornava imprestável o método histórico cujo princípio básico consistia em compreender o passado a partir das etapas do desenvolvimento dos fenômenos de conhecimento vinculando os acontecimentos às intenções dos sujeitos históricos. ${ }^{21}$

${ }^{19}$ A metáfora do bronze encontra-se no prefácio à segunda edição das Regras do método sociológico.

${ }^{20}$ DURKHEIM, Emile. As regras do método sociológico. Trad. Margarida G. Esteves. São Paulo: Abril cultural, 1978. (Os pensadores). p. 78.

21 Os historiadores da escola metódica utilizavam o método hermenêutico psicológico para a interpretação dos documentos. Por este procedimento, o sentido correto de um texto aparece quando descobrimos o que se passava na mente de 
As repercussões desta nova possibilidade foram bastante amplas; mas o movimento seguinte foi aplicar o mesmo pressuposto da nova totalidade. Afirmava que,

Se como nos concedem, essa síntese sui generis que é uma sociedade qualquer dá origem a fenômenos novos, diferentes dos que ocorrem nas consciências solitárias, é necessário admitir que esses fatos específicos residem na sociedade que os produz e não nas suas partes, quer dizer, nos seus membros. ${ }^{22}$

Em suma, implicava em demonstrar que a totalidade social apresenta certos aspectos intangiveis aos usuários do método histórico, uma vez que eles se dedicam a investigar os elementos anteriores à formação do fenômeno que estudam. A conclusão era de que não seria possivel verificar a essência das sociedades, investigando e narrando a história dos sujeitos que as formam, assim como é impossivel verificar a dureza do bronze, examinando os três elementos que o compõe. Tratava-se da inversão completa do procedimento estabelecido. Era a demonstração mais soberba a respeito dos limites inerentes ao saber histórico. Implicava evidenciar, em outros termos, a "insignificância" da influência do sujeito sobre a sociedade.

A tese durkheiminiana contrariava diretamente pressupostos básicos do modelo de compreensão histórica, gerando uma espécie de efeito dominó em relação aos princípios metodológicos fundamentais deste campo de investigação. Primeiramente, indicava não ser necessário conhecer as etapas principais do desenvolvimento de uma sociedade, nem restabelecer as suas conexões históricas fundamentais para conhecê-la. A consequência imediata era de que o procedimento histórico tornava-se supérfluo para o estudo dos fenômenos sociais. Daí decorria o desprestígio da prova documental que permitiu aos durkheiminianos argumentar, por exemplo, que se alguma sociedade representa-se “... como

um autor no momento em que escrevia. Um dos grandes representantes desta compreensão da hermenêutica é F. Schleiermacher.

22 DURKHEIM, Emile. Op. cit. p 78. 
saída de um animal epônimo, é porque forma um destes grupos especiais que se dá o nome de clã". ${ }^{23}$

O historiador metódico indagaria pela data e pelo sujeito que deu o nome a tal sociedade e pediria a apresentação de documento escrito, confiável, elaborado por pessoa digna de fé. O sociólogo durkheiminiano responderia que a existência de tal documento não faria a menor diferença porque: “... para compreender a maneira como uma sociedade se representa a si própria e ao mundo que a rodeia, precisamos considerar a natureza da sociedade e não a dos particulares" ${ }^{24} \mathrm{~A}$ proposta de Durkheim, representada pela metáfora do bron$z e$, desprestigiou o reinado da fonte escrita ao mesmo tempo em que atirou a recuperação das intenções do sujeito histórico ao plano da insignificância. Era a demonstração clara de que a sociedade pode ser compreendida sem o recurso às evidências intencionais deixadas na história pelos sujeitos concretos.

De fato, o conceito de documento escrito vincula-se profundamente à noção de sujeito porque, segundo o método da crítica das fontes, o procedimento básico utilizado pelos historiadores metódicos, para saber da validade de certo texto, se faz necessário perguntar pelo individuo que o produziu. Partia-se do pressuposto de que autores sérios e confiáveis não produzem escritos duvidosos e mal intencionados.

O princípio da confiabilidade no testemunho representava a possibilidade da reconstrução exata dos acontecimentos passados e, por conseguinte, a certeza de atingir os fenômenos na sua originalidade, ou seja, de captá-los na pureza dos seus nascedouros. Era a proposta da história ciência, também conhecida como historicismo.

O sujeito histórico era fundamental para a compreensão historicista porque esta entidade funcionava como prova de intencionalidade ${ }^{25}$, testemunho e endosso da fonte. Po-

\footnotetext{
${ }^{23}$ DURKHEIM, Émile. Op. cit. p 79.

${ }^{24}$ Idem, ibidem.

${ }^{25} \mathrm{O}$ recurso à intencionalidade dos sujeitos sempre foi uma prova fraca porque as intenções só podem ser deduzidas, a não ser que os objetivos do autor estejam expressos nos documentos, o que é bastante raro. Mesmo assim, pode-se
} 
demos ilustrar tal função a partir, por exemplo, deste texto escrito por Leopold von Ranke sobre as colônias americanas. Ranke escreveu:

... o espetáculo que os espanhóis assinalaram com maior frequência entre os povos do outro hemisfério, era viverem uns em um sistema de organização estatal e outros nas condições mais primitivas e selvagens. A pergunta sobre como se formaram os primeiros reveste-se de importância básica para o nexo de sentido da História Antiga, mas a resposta é quase impossivel. ${ }^{26}$

A tese da falta de registros escritos entre os ameríndios, ou o não reconhecimento de escritores e testemunhos autorizados no "hemisfério do outro", ${ }^{27}$ conduziu esse historicista a concluir pela possibilidade remota de se investigar a origem da formação dos sistemas estatais indígenas. Ranke parece decretar a impossibilidade desta gênese, mas não negou a probabilidade da escrita da história das Américas porque a instituição estatal serviria como evidência suficiente para narrar os acontecimentos posteriores ao "descobrimento". Assim, "... só a sua existência já era significativa e desempenhou papel importante, até na nova etapa de desenvolvimento que para eles ia começar". ${ }^{28}$

O que Ranke escreve em seguida evidencia a função desempenhada pelo sujeito histórico na construção do saber historicista. Assegura que,

Se os primitivos habitantes das Américas do Sul e Central fossem todos selvagens, é bem provável que os espanhóis pudessem manter-se lá, mas certamente não teriam expansão tão rápida e brilhante como a que tiveram. Para tanto era necessária a existência de formações estatais, com certo ní-

\footnotetext{
argumentar que o produtor do documento pode alegar certa intenção que não é a verdadeira. Cumpre destacar, mais uma vez, que este procedimento de buscar a decifração das intenções do autor é característico de uma hermenêutica psicologizante.

${ }^{26}$ HOLANDA, Sérgio Buarque de. Leopold von Ranke: História . São Paulo: Ática, 1979, p. 108.

${ }^{27} \mathrm{~A}$ América.

${ }^{28}$ HOLANDA, Sérgio Buarque de. Op. cit. p 108.

140 Revista de História Regional 14(2): 127-153, Inverno, 2009
} 
vel cultural, sujeitas a soberanos poderosos em condições de oferecer resistência... A obediência aos líderes indígenas e a ordem por eles estabelecida abririam caminho para o rei da Espanha. ${ }^{29}$

Os "Estados indígenas" servem, aqui, como lugares de evidência porque são administrados por indivíduos reais e existentes, líderes que estabelecem ordens e que são obedecidas. Sujeitos que abrem espaço para a ação do rei da Espanha, ou seja, o outro sujeito histórico cuja existência é comprovada por textos escritos. Fontes históricas, que nessa perspectiva, lançam luzes sobre sujeitos e povos que não deixaram por escrito a prova de sua existência.

Podemos, então, compreender porque Ranke escrevia história política mesmo sendo tão avesso ao envolvimento do cientista no mundo da militância partidária. Torna-se também evidente o motivo da intensa reação empreendida pelos defensores da compreensão histórica à tese durkheiminiana de que, se uma sociedade qualquer dá origem a fenômenos diferentes dos que ocorrem nas consciências solitárias, é necessário admitir que tais fatos verificam-se na sociedade que os produz e não nos indivíduos.

A negação do indivíduo, a banalização do sujeito presente nas fontes em nome da compreensão mais acurada da sociedade causou reações contrárias, mas também fascinou vários pesquisadores. Segundo Teixeira da Silva, a fundação da revista L'Anné Sociologique representou um marco na relação entre a história e as ciências sociais, e, digamos, na difusão da perspectiva da totalidade social. Durkheim passou a comandar uma "guerra de movimento" de anexação, ao campo da sociologia, de todas as disciplinas relacionadas ao estudo do fenômeno humano. ${ }^{30}$

Acontece que suas teses aproximavam-se, em parte, de outra corrente teórica igualmente fértil: o materialismo histórico. As categorias de análise durkheiminianas podiam ser tão facilmente confundidas com alguns conceitos marxistas

${ }^{29}$ HOLANDA, Sérgio Buarque de. Op. cit. p 108.

${ }^{30}$ SILVA, Fernando Teixeira da. Op. cit. p 1. 
que o autor de As formas elementares da vida religiosa formulou a seguinte advertência: "... é preciso evitar ver esta teoria da religião como simples restabelecimento do materialismo histórico: isso seria desprezar demais nosso pensamento." 31 O lembrete vinha no sentido de esclarecer que a religião, assim como outras representações sociais, é produto da síntese das consciências individuais, ou seja, da consciência coletiva e não da organização das forças produtivas como propunha Marx. A observação separava, mas a aproximação se deu no sentido de que o sujeito histórico, tal como o concebiam os praticantes do método histórico, tornou-se detalhe pequenino para a compreensão do social, tanto na perspectiva economicista quanto na sociologia durkheiminiana. Doravante, ficava interditado argumentar que os fatos determinantes da história surgiam nas intenções dos indivíduos.

Modificou-se, desta maneira, o próprio sentido que se exprimia por meio da categoria "fato". Não se trata mais de ação feita, comandada ou organizada por um sujeito. Fato social passou a significar todo fenômeno que existe ou existiu independentemente da consciência individual e que se impõe e coage.

O conceito de fato social era extensivo, portanto, também ao passado, o que afrontava diretamente o procedimento metódico dos historiadores 'tradicionais', porque, na visão durkheiminiana assim como na marxista tradicional ou estruturalista, já não importa o nome do sujeito que inventou a religião ou o capitalismo. Não interessa saber o nome da personalidade que extraiu a mais valia pela vez primeira, nem a identidade do sujeito que criou o primeiro tribunal da justiça. O importante é que estas coisas estão aí, determinando os acontecimentos.

Pode-se falar, portanto, de certa escrita da história sem sujeito, ou pelo menos, da narrativa em que o sujeito nomeado e documentalmente referido tornou-se detalhe de importância menor. Podemos dizer também que a críti-

\footnotetext{
$\overline{{ }^{31} \text { RODRIGUES, José Albertino. (Org.) Durkheim. 6 }}{ }^{a}$ ed. São Paulo: Ática, 1993. p. 171.

142 Revista de História Regional 14(2): 127-153, Inverno, 2009
} 
ca marxista em relação à neutralidade política pretendida pela escola metódica, assim como as proposições sociológicas durkheiminianas sobre a determinância do social, expuseram as fragilidades da história metódica. Evidenciaram o caráter ilusório e inexequível do projeto de reconstrução do passado tal qual efetivamente aconteceu, porque a história fundada nos feitos e ancorada em personalidades históricas revelou-se como narrativa sobre a parte ínfima dos sujeitos históricos; isto é, evidenciou-se como a narração sobre aqueles que deixaram textos escritos ou, como o registro da memória daqueles sobre os quais estas inscrições se referiam. A demonstração das falhas de uma teoria ou perspectiva pode levá-las ao descrédito e abandono, mas isso não implica a abdicação da linguagem.

O projeto histórico de reconstrução fiel do passado, além de fundamentar-se na prova documental, no testemunho e no protagonismo do sujeito, sustentava-se na possibilidade da construção de gêneses históricas. Novamente temos Leopold von Ranke como padrão. Em Deutsche Geschichte im Zeitalter Reformation, na parte que trata da unidade dos povos romanos e germânicos e de sua evolução, afirma que:

... no início de sua aventura, logo no começo da migração dos povos, o rei visigodo Ataulfo concebeu a transformação do mundo latino em um reino godo, do qual se proclamaria Cezar e onde conservaria as leis romanas... Dessa união nasceram seis grandes povos; em três predominou o elemento românico: no francês, no espanhol e no italiano. Em três, o germânico: no alemão, no inglês e no escandinavo. ${ }^{32}$

A gênese da Europa, como se vê, encontra-se na mente do sujeito chamado rei Ataulfo. A teoria e a metodologia usada pelos historicistas podem ser falhas, mas o sentido se completa. Aquele que lê compreende o enunciado, pois é perfeitamente plausivel pensar que todas as coisas têm origem em algo.

Nos textos sobre a gênese dos faxinais não se apresentam indagações sobre a mente que originou o sistema, mas

${ }^{32}$ HOLANDA, Sérgio Buarque de. Op. cit. p. 65. 
a indagação sobre o nascedouro, o berço, a terra natal do sistema é evidente. Estaria a grande gênese do sistema encarnada em alguma tribo ancestral europeia ou era prática exercida pela ancestralidade ameríndia? Parece ser esta a dificuldade e a fonte das divergências dos pesquisadores, e investigadores (diga-se que a maior parte deles não é composta por historiadores) em relação à origem dos faxinais.

Os investigadores das origens nutrem-se destas questões. Partem do princípio de que nada existe por acaso, sendo possivel elencar alguns motivos que os animam a investigar as gêneses. O primeiro consistiria em pressupor que, na origem, encontra-se a essência pura dos fenômenos e, uma vez que o tempo modifica tudo, seria necessário reencontrar a identidade primeira. O segundo implicaria calcular que, na origem, as coisas eram completas por serem criações originais, perfeitamente concebidas por seu criador ou instituidores. Por fim, julgariam que, na origem, está a verdade obscurecida pelo turbilhão discursivo que veio depois. Então, na escrita sobre os faxinais, poderiamos detectar os esforços para a definição da identidade, da originalidade e da completude, ou seja, o empenho de conceituação. Mas não nos cabe adivinhar as intenções de quem escreve. ${ }^{33}$ Por isso descartamos o entendimento pelo escopo dos autores assim como a ideia do sujeito fundador. Não faz muito sentido alguém se perguntar, ou se lançar numa investigação com o objetivo de encontrar o sujeito que inventou o sistema de faxinal.

A julgar pelos textos, uma das tentativas de resolução do problema consiste em substituir tal figura instituidora por alguma noção um tanto bizarra do tipo "sujeito coletivo". ${ }^{34}$ No caso, a sociedade romana, o povo germânico, a organização social indigena, os jesuítas, a cultura cabocla e assim por diante. Então, a gênese pode ser recomposta, mas a perspectiva hermenêutica nos conduz à seguinte questão: será mesmo necessário procurá-la?

\footnotetext{
${ }^{33}$ Este é o procedimento característico dos hermeneutas psicológicos.

${ }^{34}$ O personagem chamado Smigol, da trilogia Senhor dos Anéis, encarna a figura do sujeito coletivo uma vez que sendo o último sobrevivente de sua espécie referese a si mesmo sempre na primeira pessoa do plural. 
A resposta, quando se adota o pressuposto de que o faxinal é parte da totalidade histórica, será afirmativa simplesmente porque a compreensão, o sentido dado às coisas se completa sempre que relacionamos alguma parte ao seu todo. O método 'história', às vezes displicentemente chamado de historicismo, repousa neste dispositivo básico de construção e reprodução dos sentidos históricos: a história é o todo; os fatos ou acontecimentos representam as partes. Sempre que relacionamos algum fragmento ao conglomerado do qual foi extraído, a atribuição de sentido se completa. Mas é preciso ficar claro que a compreensão histórica é uma entre outras perspectivas a possibilitar o estabelecimento das conexões que nos permitem a captação e a construção dos significados. Devemos esclarecer também que a história exerce certo fascínio, por tradição, isto é, que não deriva somente da academia e da intelectualidade; deslumbra muitos investigadores.

Podemos dizer o mesmo da interpretação sociológica durkheiminiana, à qual nos referimos anteriormente, das proposições derivadas do materialismo dialético (principalmente daquelas em que o aspecto econômico é tomado como a totalidade) e de outras, que não vem ao caso citar. O nexo histórico, porém, talvez seja o mais arrebatador dentre todos, devido à sua profunda inserção no próprio cotidiano. As pessoas contam e ouvem histórias, ao passo que, relativamente, pouca gente faz pesquisa utilizando a análise social ou econômica.

Não causa espanto, assim sendo, que a investigação da origem seja considerada como procedimento natural e que torne a ser utilizada, sob outros ângulos, com outras roupagens e ancorada em distintas justificativas. É que a compreensão histórica torna-se útil e utilizável, tanto nas conversas informais, quanto no espaço dos procedimentos metódicos. Trata-se de recurso trivial, mas, ao mesmo tempo, indica uma forma de responder aos desafios do non sense, até mesmo quando se investiga a história da história. A averiguação das origens desse saber aponta o mundo europeu como contexto original dos procedimentos e da sensibilidade histórica, 
mas a perspectiva genealógica pode indicar outras balizas.

Podemos dizer que o século XIX e o início do XX, de Simiand, de Seignobos, de Ranke, de Durkheim e de Marx, nossa porta de entrada, foi o palco de uma dispersão, como diz Foucault. Época das misturas e das bastardias, do homem-amálgama. O europeu, segundo o autor, sentia-se um bárbaro, que se deparava com cidades em destroços e monumentos incompreensiveis. Não era por efeito das guerras e das lutas armadas. Tratava-se da colisão de certas forças muito mais sutis e não menos devastadoras. Naquele cenário, personagens letárgicos perguntavam-se pelos deuses que antigamente habitaram os templos vazios diante de seus olhares. Mais que isso, aqueles europeus, por mais reflexivos que se mostrassem, não sabiam o que eram. Ignoravam que 'raças' se misturaram para formar seus corpos, para constituir seu sangue; procuraram pelos papéis que poderiam exercer; eles não tinham individualidade. Como diz o autor da Microfisica do poder, o século XIX só poderia ser virtualmente historiador. ${ }^{35}$

A pesquisa da origem, o resgate do sujeito e o esforço para determinar as identidades, portanto, não emergem num instante de lucidez ou por meio da inventividade de algum gênio criador. Trata-se, muito mais, de uma série de reações frente ao sentimento do vazio, à tomada de consciência sobre o tempo que se esvai e sobre a fraqueza da memória. Por conseguinte, é uma tentativa de esconjurar o esquecimento, destas que se revelam como estrondosos fracassos, quando se retrocede demasiadamente no tempo. As certezas de que a recorrência ao nascedouro é fundamental para o verdadeiro conhecimento dos fenômenos mostraram-se como puras ilusões.

A confiança na grandiosidade dos surgimentos originais transformou-se em descrédito por meio da descoberta gradual de que todo início é insignificante e quase impercep-

${ }^{35}$ Confira FOUCAULT, Michel. Microfisica do poder. Rio de Janeiro: Edições graal. 1979. p. 32. 
tível. É a metáfora nietzscheniana da careta e do macaco, ${ }^{36}$ que está no início de tudo o que é humano. Por fim, a certeza de que, na origem, encontra-se a verdade e que ela foi obscurecida pelo turbilhão discursivo que veio depois cede lugar à constatação de que, longe de encontrar-se no princípio das coisas, a verdade tem sua própria história.

Assim, o inquérito da linhagem defrontou-se com outra das suas mais poderosas críticas: a genealogia nietzscheniana. A proposta sociológica durkheiminiana não foi alternativa eficaz porque, apesar de possibilitar a compreensão do social sem a recorrência à origem, excluía a figura do sujeito. O mesmo diga-se do economicismo. Mas é preciso considerar que a genealogia e a perspectiva hermenêutica não surgiram para recuperar o sujeito perdido mas para permitir a percepção do recurso à intencionalidade, da pesquisa da origem e da construção de totalidades como procedimentos recorrentes para a construção dos sentidos. As tentativas de esconjurar a grande amnésia que mitiga a memória dos começos, no entanto, persistem, retornam e reaparecem.

O retorno ao sujeito histórico pode ser mais frequentemente vinculado à crítica da estruturalização do pensamento $^{37}$ e, no campo da produção historiográfica, recebe algumas nomeações do tipo "história vista de baixo", "história dos excluídos", "micro história" e, mais amplamente, aquilo que alguns têm chamado de história cultural. Ilustremos com um escrito.

Jim Sharpe fecha artigo sobre a historiografia inglesa das últimas décadas com o seguinte enunciado: "a história vista de baixo ajuda a convencer aqueles de nós nascidos sem colheres de prata em nossas bocas, de que temos um pas-

\footnotetext{
${ }^{36}$ Para Nietzsche, o macaco é a figura de antítese do super homem. No prólogo do Zaratrustra escreveu:" O que é o macaco para o homem? Uma risada ou uma dolorosa vergonha. E é isso mesmo que o homem deve ser para o super homem: uma risada ou uma dolorosa vergonha". O símio é, então, uma figura do eterno retorno.

${ }^{37} \mathrm{O}$ estruturalismo pode ser considerado como outra forma de estabelecimento do sentido do mundo em que uma estrutura qualquer constitui o todo e as conjunturas e fatos são as partes.
} 
sado, de que viemos de algum lugar". ${ }^{38}$ Podemos pensar em Sharpe como parte daquele grupo ao qual se referia Foucault. Não mais a Europa do século XIX. Trata-se de gente que vive ou viveu no tempo mais recente, que não nasceu com as famosas pratarias nas mesas requintadas e ignora a mistura de raças que engendrou seus corpos, e formou seu sangue; procura que papéis poderia exercer e julga não ter individualidade.

Sharpe mesmo apresenta os protagonistas desta perspectiva do resgate do passado: o primeiro deles é Edward Thompson, que, em 1966, plastificou tal anseio publicando The Histoy from Below. Thompson escreveu, mais tarde, que estava:

procurando resgatar o pobre descalço, o agricultor ultrapassado, o tecelão do tear manual 'obsoleto'... Suas habilidades e tradições podem ter-se tornado moribundas. Sua hostilidade ao novo industrialismo pode ter-se tornado retrógrada. Seus ideais comunitários podem ter-se tornado fantasias... mas eles viveram nesses períodos de extrema perturbação social, e nós, não. ${ }^{39}$

Em segundo e terceiro lugar, Sharpe apresenta os trabalhos de Emmanuel Le Roy Ladurie sobre a comunidade camponesa de Montaillou e a escrita de Carlos Ginzburg sobre o moleiro Domenico Scandella. Por fim, refere-se aos trabalhos de Alan Macfarlane sobre bruxaria e do norte americano Eugene D. Genovese sobre identidade negra nos Estados Unidos.

O texto de Sharpe, no entanto, é entretecido (entristecido) por certa elegia do lamento, traduzida por uma série de obstáculos e problemas a serem enfrentados para a escrita da história. Primeiramente, aponta os problemas a serem transpostos pelos historiadores da história social, principalmente a escassez das evidências. Então, chega a formular uma es-

${ }^{38}$ SHARPE, Jim. A história vista de baixo. In: BURKE, Peter. (Org.) A escrita da história: novas perspectivas. São Paulo: Editora da universidade Estadual Paulista, 1992. p. 62.

${ }^{39}$ SHARPE, Jim. Op. cit. p.p. $41-42$.

148 Revista de História Regional 14(2): 127-153, Inverno, 2009 
pécie de lei: 'quanto mais para trás vão os historiadores, buscando reconstruir a experiência das classes sociais inferiores, mais restrita se torna a variedade de fontes à sua disposição'. No máximo, se pode recuar até a Revolução Francesa. Além disso, a história dos sujeitos comuns, neste caso, como destacou Hobsbawm, restringe-se aos ancestrais do movimento trabalhista. Então, a consciência desapontada do pesquisador da origem lamenta e deplora tais impedimentos, mas pode ser que, ampliando a gama dos sujeitos históricos, o problema se dissolva.

As tentativas de Ladurie e de Ginzburg surgem como alternativas por que: o primeiro investiga comunidade de camponeses e, o segundo, certo sujeito, um indivíduo que o possibilita recuar a história até o século XVI. Mas, Sharpe retoma o hino das lamentações. Infelizmente, escreve ele, os pesquisadores que tendem à micro história podem obscurecer a totalidade, restringindo-se ao local, fragmentando, estilhaçando, e caindo naquilo que se chamou de história em migalhas. A história oral seria tentativa inútil porque o pesquisador que adota este procedimento “... tem problemas óbvios ao tratar com pessoas que morreram antes de serem gravadas ou cuja memória foi perdida por seus sucessores e o tipo de testemunho direto que pode obter é negado aos historiadores dos periodos mais antigos". 40

A lamúria estende-se, igualmente, para todas as tentativas de pesquisa que se aproximam, de uma forma ou de outra, das metodologias antropológicas, principalmente, da perspectiva utilizada por Clifford Geertz. E, do lamento, a cantiga evolui para a apresentação dos perigos e a listagem das ameaças: "... permanece o perigo de se cair em algo como a fragmentação do conhecimento histórico e a despolitização da história"; risco ameaçador, principalmente, para a história social (europeia) de cair no "... antiquarismo de esquerda" e de tender para a "reunião e publicação de coisas sem importância da vida da classe trabalhadora".

${ }^{40}$ Idem. p. 49 
Lamúrias autênticas? Temores reais? Na Europa, que tenta reencontrar as origens, certamente... Tais sentimentos devem fazer sentido. Para nós, que não precisamos regressar tão longe na linha do tempo, a 'lei' da 'escassez proporcional à distância temporal' não será ameaça muito séria. Do mesmo modo, a tese de que não podemos entrevistar sujeitos que morreram há vários séculos não deverá causar compunção, porque nem precisamos atribuir tanta importância à origem. A despolitização da história resolve-se pela escrita da história dos marginalizados. E por fim, a perspectiva hermenêutica nos ensina que a fragmentação das totalidades e a construção de outros conjuntos de sentidos são procedimentos históricos.

Os pesquisadores das origens podem dar-se o luxo de travar debates para responder questões do tipo: a história dos faxinais começa na Europa ou entre os indígenas? Os faxinalenses, no entanto, também contam histórias. Eles asseguram que aqui, na região dos pinhais ${ }^{41}$, “... já tinha cerca pra mais de cem anos. Os antigos se acertavam e onde precisava fazer uns vãos de cerca, derrubavam um pinheiro ou imbuia e ali mesmo lascavam e construíam... O faxinal começava nestes fundões e ia encostando cerca...". ${ }^{42}$

O faxinalense também conta história sem sujeito, porque não apresenta o nome do fundador, do inventor do sistema de faxinais. Não há investigação da origem, nem preocupação com documentos, muito menos alguma ansiedade com as relações que se estabelecem com a sociedade como um todo. O historiador da cultura, portanto, tem um campo vasto para estudar, conhecer e tornar conhecidas as relações que estes sujeitos estabelecem com os objetos, com o mundo natural, o sobrenatural e com a própria história. Mas, além disso, hermeneuticamente pode reconhecer-se diante do outro.

A escrita da história cultural na perspectiva hermenêutica caracteriza-se como atitude filosófica no sentido de evitar

\footnotetext{
${ }^{41}$ Região central do Estado do Paraná.

${ }^{42}$ Depoimento colhido de D. S., por Roberto Martins de Souza.

150 Revista de História Regional 14(2): 127-153, Inverno, 2009
} 
as armadilhas da linguagem porque se sustenta na evidência de que o sentido é sempre construído a partir do horizonte já dado. O panorama que nos serve para a compreensão dos fenômenos históricos, entretanto, não se resume ao quadro teórico adotado para a análise. Que os referenciais teóricos nos são transmitidos e determinam o resultado do trabalho historiográfico, já sabemos e admitimos. A perspectiva hermenêutica, todavia, demonstra que o conjunto de palavras às quais recorremos para significar o mundo, para expressálo é igualmente transmitido e acaba impondo o conteúdo e a forma do que dizemos e escrevemos. Trata-se da chamada história residual: o horizonte que dita o que expressamos.

O reconhecimento desta espécie de 'campo de força' que envolve os objetos, porém, não impede que sejam investigados e representados na perspectiva histórica. Obriga, sim, o intérprete/investigador a incluir-se no fazer interpretativo, que, para além de um ponto de vista, se expressa sempre a partir de tradições tais como a pesquisa da origem, o resgate do sujeito e a manutenção de certas totalidades. Tal constrangimento não implicará o empobrecimento da compreensão. Provocará, efetivamente, riqueza maior no resultado da investigação pela exposição das tradições, o que implica no deslocamento do olhar investigativo para a construção dos sentidos. Isto significa dizer que se abdica da velha tentativa historicista de reconstruir as cadeias de fatos 'tal qual aconteceram'. Por consequência, as investigações de origem tornam-se empreitadas dispensáveis, cedendo lugar a uma escrita que ratifica: a pluralidade das manifestações culturais, seus valores, seus acertos e seus erros, seus conflitos e suas experiências. A cultura será assim concebida como o conjunto das relações que os grupos e os sujeitos estabelecem com os objetos, com a natureza, com o 'sobrenatural' e com a própria história. 


\title{
A hermenêtica e a origem dos faxinais
}

\author{
José Adilçon Campigoto \\ Aldo Nelson Bona
}

Resumo: As relações entre a produção do conhecimento histórico e a arte da interpretação, a partir das ponderações feitas por Hans-Georg Gadamer, em Verdade e método, abraçando a hermenêutica como atitude investigativa, são discutidas no presente texto. O ponto de partida para a ancoragem da interpretação é um objeto palpável: o sistema de faxinal, existente na região sul do Brasil, que consiste em certo modo de utilização comum das terras para a criação de animais e que se tem classificado como manifestação cultural pertencente à categoria dos povos tradicionais. Trata-se de fenômeno que vem merecendo a atenção de cientistas vinculados a várias áreas do conhecimento, que buscam, pela investigação, o reconhecimento legal destes chamados grupos marginais. Não é diferente o desafio encarado pelos historiadores da cultura. O objetivo deste artigo, mais do que compreender a construção do sentido histórico desse modo de organização, consiste em investigar como se conta a história dos faxinais (e por extensão, dos povos excluídos) num momento que representa, pelo menos para alguns, a aceleração do desaparecimento do sistema.

Palavras-chave: hermenêutica; faxinal; origem.

Abstract: The elaboration to historical knowledge and the your connection to the art to interpreting, from considerations made by Hans-Georg Gadamer in Truth and method, having the Hermeneutics as investigative attitude, are discussed in this text. The starting point for the anchoring of interpretation is a factual object, it is: faxinal system, existing in the region southern Brazil, which consists of a way to use the common land for the create of animals; it classified as expression cultural belonging to traditional people's category. It's phenomenon that have merited the attention 
of scientists belonging to different knowledge areas, seeking, through research, the legal recognition of these so-called marginal groups. It's the challenge accepted by historians of culture. In this paper, rather than understanding the historical construction of this way of organization, we will investigate as to the history of faxinais (and by extension, of marginalized people) in a time that represents, at least for some, the climax of the disappearance of the system.

Keywords: hermeneutics; faxinal; source.

Artigo recebido para publicação em 11/11/2009

Artigo aceito para publicação em 10/12/2009 